Zeneca, Astro, Celgene Corporation, Celtrion, Eli Lilly, Glaxo, ILTOO, Janssen, Medlmmune, MSD, Novartis, Pfizer, Roche, Samsun, Sanofi, UDB, Speakers bureau: AbbVie, Amgen, Astra-Zeneca, Astro, Celgene Corporation, Celtrion, Eli Lilly, Glaxo, ILTOO, Janssen, Medlmmune, MSD, Novartis, Pfizer, Roche, Samsun, Sanofi, UDB, Klaus Machold Grant/ research support from: Abbvie

DOI: 10.1136/annrheumdis-2019-eular.4148

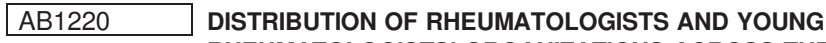 RHEUMATOLOGISTS' ORGANIZATIONS ACROSS THE WORLD: STILL ROOM FOR IMPROVEMENT}

$\underline{\text { Aurelie Najm }}^{1}$, Julia Spierings ${ }^{2}$, Savino Sciascia $^{3}$, Elena Nikiphorou ${ }^{4}$, Alexandre Sepriano ${ }^{5}$, Alessia Alunno ${ }^{6}$, EMEUNET Working Group. ${ }^{1}$ Rheumatology Nantes University Hospital and Nantes University of Medicine INSERM UMR1238, Nantes, France; ${ }^{2}$ Department of Rheumatology and Clinical Immunology, University Medical Center Utrecht, Utrecht, Netherlands; ${ }^{3}$ Center of Research of Immunopathology and Rare Diseases, Department of Clinical and Biological Sciences, University of Turin, Turin, Italy; ${ }^{4}$ Department of Inflammation Biology, King's College London, London, United Kingdom; ${ }^{5}$ Leiden University Medical Center, London, Netherlands; ${ }^{6}$ University of Perugia, Perugia, Italy

Background: Rheumatology is a rapidly advancing specialty. The increasing understanding of autoimmune mechanisms and advanced therapies have improved care for patients with chronic inflammatory conditions immensely. National and international collaborations are growing and are key to scientific developments. Still, the number and geographical distribution of rheumatology organizations globally, is not known.

Objectives: To gain further insights into the distribution of established and young rheumatologists' organizations beyond Europe. Furthermore, we intended to explore correlations between presence of rheumatology organizations and demographic and socio-economic parameters.

Methods: A systematic online search was performed independently by three investigators (AN, SS, JS). Keywords used in the search related to three main themes (i) Rheumatology (rheumatology or rheumatologist(s) or rheumatism), (ii) Organizations (associations or young organization or society or group or association or league or federation) and (iii) country's name. All identified rheumatology organizations worldwide were reported. Countries were grouped in eight regions according to their geographic location. General demographic information (including population, area, pop. density, net migration, infant mortality, GDP, literacy, phones, arable, crops, climate, birth-rate, death rate) was retrieved from World Bank Open Data by one extractor (SS). Descriptive statistics and quartile distribution for each analysed variable were performed using Excel ${ }^{R}$ (Microsoft $^{-}$ Office) and SPSSR software ${ }^{R}$, using the total number of countries per region as the denominator.

Figure 1. Overview of the percentage of national rheumatology societies

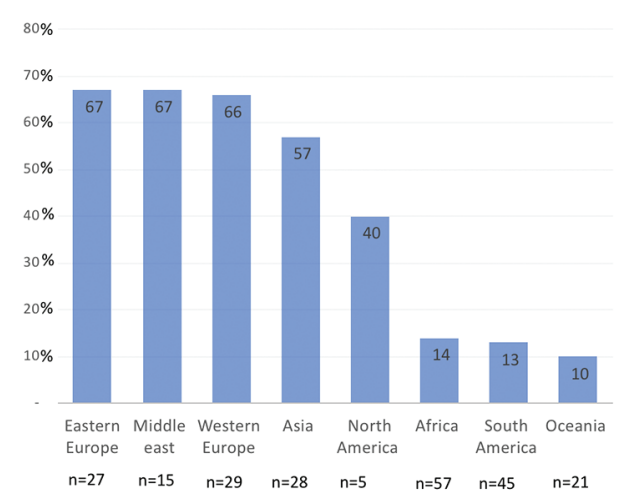

$\mathrm{n}$ is the number of countries (including islands) per geographical area.

Figure 1

Results: Four international societies and three junior international organizations (EMEUNET, PANLAR joven, ALPAR Young rheumatologists) were identified. Out of the 227 countries assessed, 89 national rheumatology societies $(39 \%)$ and seven junior national organizations were identified $(n=4,2 \%)$. Rheumatology societies were more frequent in Eastern Europe $(n=18 / 27,67 \%)$, Middle east $(n=10 / 15,67 \%)$ and Western Europe $(n=19 /$ $29,66 \%$ ) (Figure 1). Rheumatology societies were more frequently found in countries in the upper quartiles (Q1) of population density, gross domestic product and literacy when compared to Q2-4 (as assessed for each variable, $p<0.05$ ). Conversely, it was significantly less frequent in countries with high migration and infant mortality (Q1 Vs Q2-3, $p=0.043$ and $\mathrm{p}=0.039$, respectively).

Conclusion: National rheumatology societies were identified in less than half the countries across the globe and were unequally distributed. We only found 7 national young organizations. Such organizations are needed, as trainees can highly benefit from educational and networking offers. Further steps will include the exploration of the impact and the reasons for lack of such establishments in some countries.

Disclosure of Interests: Aurelie Najm: None declared, Julia Spierings Grant/research support from: Boehringer Ingelheim, Savino Sciascia: None declared, Elena Nikiphorou: None declared, Alexandre Sepriano: None declared, Alessia Alunno: None declared

DOI: 10.1136/annrheumdis-2019-eular.4917

\begin{tabular}{|l|l}
\hline AB1221 & VIEWS OF PRIMARY CARE PHYSICIANS AND \\
RHEUMATOLOGISTS REGARDING SCREENING FOR \\
HYPERLIPIDEMIA AMONG PATIENTS WITH \\
RHEUMATOID ARTHRITIS
\end{tabular}

Iris Navarro-Millan ${ }^{1,2}$, Anna Cornelius-Schecter ${ }^{1}$, Ronan O'beirne ${ }^{3}$, Melanie Morris ${ }^{3}$, Geyanne Lui ${ }^{1}$, Susan Goodman ${ }^{2}$, Andrea Cherrington ${ }^{3}$, Liana Fraenkel ${ }^{4} .{ }^{1}$ Weill Cornell Medicine, New York, United States of America; ${ }^{2}$ Hospital for Special Surgery, New York, United States of America; ${ }^{3}$ University of Alabama at Birmingham, Birmingham, United States of America; ${ }^{4}$ Yale University, New Haven, United States of America

Background: Screening of hyperlipidemia in rheumatoid arthritis (RA) is suboptimal, despite RA patients' high risk for cardiovascular disease (CVD) mortality.

Objectives: To identify barriers to screening for hyperlipidemia among patients with RA from the viewpoint of primary care physicians (PCPs) and rheumatologists.

Methods: We recruited rheumatologists and PCPs nationally to participate in separate moderated structured group teleconference discussions using the nominal group technique. Participants in each group generated lists of barriers to screening for hyperlipidemia in patients with RA, then each selected the three most important barriers from this list.

Results: Twenty-six rheumatologists participated in 3 groups and 20 PCPs participated in groups. The resulting barriers were organized into physician-, patient- and system-level barriers. Rheumatologists prioritized physician level barriers (e.g. 'ownership' of hyperlipidemia screening), whereas PCPs prioritized patient-level barriers (e.g. complexity of RA itself). See table 1 for details.

Conclusion: These rheumatologists were conflicted about whether screening of CVD risk among patients with RA should fall within the role of the rheumatologist or PCPs. On the other hand, participating PCPs were concerned about the overall effect of RA and RA treatments in the context of screening hyperlipidemia.

Table 1221. Screening for hyperlipidemia: List of themes and sub-themes of barriers for rheumatologists and primary care physicians (PCPs) to screen patients with RA, with their respective priority votes

\begin{tabular}{|c|c|c|c|}
\hline Category & Subcategory & $\begin{array}{c}\text { Rheumatologist } \\
\text { (\% votes) } \\
\text { Total Votes } \\
N=162\end{array}$ & $\begin{array}{c}P C P \\
\text { (\% votes) } \\
\text { Total Votes } \\
N=120\end{array}$ \\
\hline \multirow[t]{6}{*}{$\begin{array}{l}\text { Physician } \\
\text { Level }\end{array}$} & Total Votes & 83.0 & 42.5 \\
\hline & Lack of time & 34.0 & 1.7 \\
\hline & $\begin{array}{l}\text { Conflict regarding ownership of } \\
\text { hyperlipidemia screening }\end{array}$ & 25.9 & 10.8 \\
\hline & $\begin{array}{l}\text { Lack of training and knowledge of } \\
\text { hyperlipidemia guidelines or RA itself }\end{array}$ & 17.9 & 20.0 \\
\hline & Focus only in RA & 4.9 & - \\
\hline & $\begin{array}{c}\text { Physician prioritization of RA symptomology } \\
\text { over preventive measures }\end{array}$ & - & 10.0 \\
\hline \multirow{8}{*}{$\begin{array}{l}\text { Patient } \\
\text { Level }\end{array}$} & Total Votes & 7.5 & 44.2 \\
\hline & Effect of RA and its treatment & 2.5 & 9.2 \\
\hline & $\begin{array}{l}\text { Patient prioritization of RA symptomology } \\
\text { over preventive measures }\end{array}$ & 2.5 & 9.2 \\
\hline & Patient expectations & 1.9 & - \\
\hline & Patient already on multiple medications & 0.6 & 0.0 \\
\hline & Multiple blood draws & 0.0 & 8.3 \\
\hline & $\begin{array}{l}\text { Side effects of statins and drug interactions } \\
\text { with statins }\end{array}$ & 0.0 & 5.0 \\
\hline & Poor patient compliance with medical care & 0.0 & 9.2 \\
\hline
\end{tabular}




\begin{tabular}{lccc} 
& Patients' lack of awareness of CVD risk & - & 3.3 \\
System & Total Votes & 9.9 & $\mathbf{1 3 . 4}$ \\
Level & $\quad$ Lack of care coordination & 6.8 & 11.7 \\
& $\begin{array}{l}\text { Financial barriers (limited insurance } \\
\text { coverage, cost of repeating labs) } \\
\text { Lack of financial incentive for screening }\end{array}$ & 3.1 & - \\
& - & 1.7 \\
\hline
\end{tabular}

Note: RA = rheumatoid arthritis; CVD = cardiovascular disease; $0 \%=$ that subtheme emerged during the brainstorming session but did not receive votes; " - " = the sub-theme did not emerge in the respective group.

Disclosure of Interests: Iris Navarro-Millan: None declared, Anna Cornelius-Schecter: None declared, Ronan O'Beirne Grant/research support from: Pfizer, Inc., Melanie Morris: None declared, Geyanne Lui: None declared, Susan Goodman Grant/research support from: Novartis: research support, Consultant for: Novartis, UCB, Pfizer: consulting, Andrea Cherrington: None declared, Liana Fraenkel: None declared

DOI: 10.1136/annrheumdis-2019-eular.1827

\section{AB1222 PATIENT PREFERENCES FOR THE USE OF DIGITAL TOOLS AND SOCIAL MEDIA IN DIET AND EXERCISE INTERVENTIONS}

W. Benjamin Nowell ${ }^{1}$, Kelly Gavigan ${ }^{1}$, Jeffrey Curtis ${ }^{2}$, Shilpa Venkatachalam ${ }^{1}$, Francois Ban', Amin Yakubu', Alexis Ogdie ${ }^{3} .{ }^{1}$ Global Healthy Living Foundation, Upper Nyack, United States of America; ${ }^{2}$ University of Alabama at Birmingham, Birmingham, United States of America; ${ }^{3}$ Perelman School of Medicine, University of Pennsylvania, Philadelphia, United States of America

Background: Healthy behavior changes such as improving diet/exercise are important to improve outcomes in rheumatic and musculoskeletal disease (RMD) patients. These changes require incentives, whether internal or external motivation or social support.

Objectives: To assess feasibility of using digital symptom tracking and social media peer support to conduct diet/exercise health behavior change interventions among adults with inflammatory arthritis (IA) and osteoarthritis $(\mathrm{OA})$.

Methods: A 37-item cross-sectional survey was developed and administered online and via mobile app in the ArthritisPower research registry. Participants (pts) were eligible if they were $\geq 19$ years of age, resided in the US, and reported physician diagnosis of IA or OA. Pts reported on use of technology and social media, experience with exercise and weight loss programs, and interest in various program features. We descriptively reported differences between respondents with IA (RA, PsA, AS) and OA. Results: 418 pts completed the survey. A majority were female $(89.5 \%)$ and white $(89.5 \%)$; mean age was 56 (10.5). The proportion of pts who were obese $(\mathrm{BMI}>30)$ was higher among $\mathrm{OA}$ than $\mathrm{IA}$ pts $(67.7 \%$ and $50.0 \%$, respectively; $p<0.001)$. Most pts were willing to provide blood samples remotely and use WiFi-enabled digital scale and blood pressure monitor for a trial (Table). Interest in social media for peer support and apps differed between IA vs. OA pts: more IA pts used an app to help them exercise $(35.1 \%$ vs. $19.2 \%$ of OA pts, $p=0.001)$ and were interested in using an app to track diet and exercise in the context of peer support on Facebook $(72.2 \%$ vs. $62.3 \%$ of OA pts, $\mathrm{p}=0.04)$. The most commonly used social media platform overall was Facebook (93.3\% of pts) followed by Twitter $(51.9 \%)$ and Instagram $(41.9 \%)$. Pts cited pain/difficulty moving $(57.4 \%)$ and sedentary behavior, such as watching TV, (47.6\%), as their biggest weight loss challenges. OA pts reported depression $(46.9 \%$, $\mathrm{p}=0.01)$ and disliking exercise $(34.6 \%, \mathrm{p}=0.003)$ as bigger challenges to weight loss than did pts with IA (34.0\% and $20.8 \%$ respectively). Motivations to exercise also differed between groups: more IA than OA pts said building muscle was a top motivation $(54.5 \%$ and $43.1 \%$, respectively; $\mathrm{p}=0.03$ ).

Table: Interest in program features by arthritis type

\begin{tabular}{lcccc}
\hline Table: Interest in program features by arthritis type & $\mathrm{n}(\%)$ & $\begin{array}{c}\text { Inflammatory } \\
\text { Arthritis } \\
(\mathrm{n}=288)\end{array}$ & $\begin{array}{c}\text { Osteoarthritis } \\
(\mathrm{n}=130)\end{array}$ & $\begin{array}{c}\mathrm{p} \text { - } \\
\text { value }\end{array}$ \\
\hline $\begin{array}{l}\text { Regularly using WiFi-enabled digital scale } \\
\text { to measure weight and blood pressure }\end{array}$ & 332 & $236(81.9)$ & $96(73.9)$ & 0.12 \\
$\begin{array}{l}\text { monitor automatically linked to study } \\
\text { Providing blood samples for study by }\end{array}$ & 320 & $222(77.1)$ & $98(75.4)$ & 0.88 \\
going to nearby Quest or other lab & $(76.6)$ & & & \\
Participating in study that would provide & 313 & $224(77.8)$ & $89(68.5)$ & $0.03^{*}$
\end{tabular}

Participating in peer support (via

Facebook private group), with other arthritis patients

Participating in peer support (via

Facebook private group), that includes patients without arthritis

Using a mobile app to track my diet and exercise

Participating in group facilitated by professional weight loss counselor

Using wireless scale that automatically

sends my weight to the counselor

Sharing my banking information so study

could provide compensation

*Statistically significant at alpha $=0.05$

Conclusion: Program focus and format may need to be tailored depending on arthritis type, but pts with both $\mathrm{IA}$ and $\mathrm{OA}$ are interested in social media peer support and digital symptom tracking to motivate achievement of health behavior change goals.

Disclosure of Interests: W. Benjamin Nowell: None declared, Kelly Gavigan: None declared, Jeffrey Curtis: None declared, Shilpa Venkatachalam: None declared, Francois Ban: None declared, Amin Yakubu: None declared, Alexis Ogdie Grant/research support from: (To my university) Novartis, Pfizer, Grant/research support from: Novartis, Pfizer, Grant/ research support from: Novartis, Pfizer, Grant/research support from: Novartis, Pfizer, Consultant for: AbbVie, Bristol-Myers Squibb, Celgene, Corrona, Eli Lilly and Company, Novartis, Pfizer, and Takeda, Consultant for: AbbVie, Amgen, Bristol-Myers Squibb, Celgene, Corrona, Eli Lilly, Novartis, Pfizer Inc, Takeda, Consultant for: Abbvie, Amgen, BMS, Celgene, Corrona, Lilly, Novartis, Pfizer, Takeda, Consultant for: Abbvie, Amgen, BMS, Celgene, Corrona, Lilly, Novartis, Pfizer, Takeda

DOI: 10.1136/annrheumdis-2019-eular.2697

\section{AB1223 A SYSTEMATIC REVIEW OF STUDIES INVESTIGATING THE EFFECTIVENESS OF ADALIMUMAB PATIENT SUPPORT PROGRAMMES}

Petra Došenović Bonča, Aleša Lotrič Dolinar, Mitja Oblak. Faculty of Economics University of Ljubljana, Ljubljana, Slovenia

Background: Adalimumab patient support programmes (A-PSPs) are offered to patients with chronic inflammatory indications creating the need to study how such A-PSPs assist patients and other stakeholders in improving health outcomes. A deeper understanding of the effects of APSPs can improve treatment outcomes and experience of patients being treated with adalimumab.

Objectives: To review current studies evaluating A-PSPs, summarize their general characteristics and methodology, and recommend future research work in the area of A-PSPs.

Methods: Studies were identified through Web of Science and were cross-checked by searching through PubMed and MEDLINE databases, following PRISMA guidelines. Full-text papers and conference proceedings identified by the database search were reviewed for relevance.

Results: 17 studies evaluating the impacts of A-PSPs on patient outcomes were identified -6 full-text articles and 11 meeting abstracts. Most research was done at the international level or in North America [1-3]. In only 5 reviewed studies a prospective study design was applied. Indications most commonly investigated were rheumatoid arthritis and inflammatory bowel disease. 12 studies evaluated the impact of all interventions of A-PSPs while others assessed the impact of Coach Care Calls or phone calls. Patient outcomes most commonly measured were persistence, adherence and low disease activity or remission. Overall, patients using any of the interventions of A-PSPs experienced significantly better improvements in all studied patient outcomes at different follow-up assessments compared to those not enrolled into any of the programme's interventions. Study population sizes and ratios between assigned users and non-users of interventions differed between studies. The most frequent follow-up assessments were after 12 and 24 months of treatment with adalimumab. Data for analysis was mostly obtained by linking a patient support database and claims administrative database, and in 5 cases by applying patient and physician reported surveys. Methodology for assessing the differences between users and non-users of interventions of A-PSPs consisted of univariate and multivariate methods, where the causal relationships between the impact of patient support program and patient outcomes were estimated by regression modelling adjusted for multiple confounders.

Conclusion: Interventions of A-PSPs have been shown to have a positive impact on all investigated patient outcomes. Main recommendations for 